Quinine useless as a thera- Antagonisticpower of quinine peutic agent.

Death occurs on the fifth day. beyon.

Yellow fever never merges into intermittent.

One attack affords an immunity from future ones.

Immunity almost perfect after a three years' residence in the lowlands.

Convalescence less protracted than in remittent fever.

Peculiar smell in yellow fever Not observable in remittent cases. fever.

These distinctions are striking; yet there are many who hesitate in determining what the points of contact and divergence are which connect and separate the various forms of malarious disorders. From their having observed yellow fever to coexist with remittent, they believe that both remittent and yellow fever are due to one and the same cause that upon a reciprocal action of various concurrent agents, and a varied mode of operation of the cause, depend the varied conditions which are observed; and they ask why should not the relation between the two conditions be one of direct causation? These inferences, however, are drawn from observations limited to the habitat of yellow fever, and consequently are not sufficiently cumulative to warrant their acceptance. For if yellow fever and remittent be the offspring of one and the same germ, then yellow fever should be found wheresoever remittent fever has existence; but yellow fever is unknown in the vast marshes at the deltas of the large rivers of the Old World, and in the many localities in which remittent fever luxuriates. This coincidence of the appearance of two disorders in one locality has likewise been noted by others. Sir James M'Grigor observed during the Peninsular war that when men were encamped by the side of some rivers, a part would fall subject to dysentery, whilst another would be attacked by ague.

Whilst doing duty as medical officer with the men of the Royal Marine Battalion, quartered at St. Jean d'Acre after the fall of that fortress, I observed that whilst a portion of them fell ill of dysentery, another succumbed to remittent fever. The same thing occurred to the men exposed to the baneful influences of the Gold Coast during the Ashantee campaign, for whilst some had fever of a remittent type, others suffered from malarious dysentery.

The advocates of the exclusive existence of one germ for the manifestation of two different diseases in one locality, allege such examples as the above in support of their theory; the poison, they say, acts variously according to the constitution and the influences reigning at the time. If we admit the theory that one cause alone is sufficient to produce different diseases as distinct in themselves as are yellow and remittent fever, we should then find ourselves in the position of being obliged to break down the barriers which now are generally admitted to divide scarlet fever from measles, yellow fever from plague, typhus fever from typhoid, rabies from hydrophobia, and to accept theories which are diametrically opposed to received opinions, and directly at issue with the facts and evidence which have been solved by accurate research and clinical observation. In the West Indies, simple continued fever and remittent fever may be found coexisting, whilst yellow fever is prevailing and doing its worst; but it does not follow, because different types of fever appear during the prevalence of a more severe one, such as yellow fever is, that any necessary causative connexion exists between them.

Whatsoever be the cause or whatsoever the germ which originates yellow fever, there is every reason to believe that it is essentially the cause or specific germ of yellow fever, differing toto celo from that which produces remittent fever or dysentery; and in the histories of the various epidemies of yellow fever which have occurred since the seventeenth century, whether deseribed by a Ferreira da Rosa, a Simaõ da Cunha, a Chisholm, a Rush, a Blair, or a Louis, this fever is stamped with an individuality which prevents it from being mistaken for plague or remittent or other fever.

Wheresoever malarious diseases have appeared they have been characterised similarly, and although some shades of difference do obtain, as in all types of fever, these diseases have always been identical, in their essential symptoms, with those from whence they have sprung, and have pre. served their individuality from ages most remote. The plague which is cradled in the delta of the Nile has always produced the symptoms of plague. Cholera, which is the child of the Sonderbunds of the Ganges, has always produced cholera. Yellow fever, which finds its birth in the delta of the Mississippi, invariably engenders yellow fever. Each has produced nothing more nor less than itself but in degree ; and as Professor Tyndall, in his lectures at the Royal Institution, has said :- "As surely as a thistle was from a thistle seed, as surely as a fig comes from the fig, the grape from the grape, the thorn from the thorn, so surely does the typhoid fever virus increase and multiply into typhoid fever, the scarlatina virus into scarlet fever, the small-pox virus into small-pox." And so with yellow and remittent fever, each distinct in itself, each having a germ sui generis, a germ endowed with like and constant properties, indicated in its effects by special symptoms during life, and specific pathological lesions revealed by examination after death. Remittent fever clothed in similar symptoms reveals itself as remittent and never as yellow fever, whilst yellow fever assumes an individuality which stamps it as a specific disease, essentially infectious in its nature, distinct and separate from remittent.

Cheltenhana.

\section{A CASE OF FREQUENT REMARKABLY HIGH TEMPERATURES DURING AND AFTER CONVALESCENCE FROM ENTERIC FEVER.}

BY HORATIO DONKIN, M.B. OxoN., SENIOR ASSISTANT-PHYSICIAN TO WESTMINGTER HOSPITAL; PHYSICIAN TO THE EAST LONDON HOSPITAL FOR CHILDREN.

THE subject of these remarks is a nurse at the East London Hospital for Children, aged nineteen, who came under my notice early in January of this year, suffering from enteric fever. She first took to her bed on Jan. 13th, having, however, had considerable diarrhœa for a week previously, and confessing to having felt very unwell since the beginning of the month. The diarrhoea continuing and a few rose spots still making their appearance, the temperature steadily rose from the morning of the 14th, till, on the 17 th, there was a morning temperature of $105^{\circ}$ and an even. ing one of $105.5^{\circ}$. On the 18 th the morning registration showed $105 \% 2^{\circ}$, while in the evening of that day a tempera. ture of only $98.5^{\circ}$ was noted in the axilla, a thermometer in the mouth shortly afterwards showing $100^{\circ}$. There was no obvious change in other symptoms with this fall, nor was there at any time evidence of danger independently of the height of the temperature. From the 19th to the 2Ist inclusive no lower temperature was remarked than $104^{\circ}$, the observations being made thrice daily; and on the evening of the 21 st the temperature rose from $105^{\circ}$ at 6 P.M. (about which point the maximum had previously been) to $109^{\circ} 4^{\circ}$ at 8.30 P.M. (On the afternoon of this day, when I saw her between 4 and 5 o'clock, the patient appeared about at her worst, being somewhat prostrate and lying low down in the bed.) According to my instructions, should the temperature rise above $105^{\circ}$, she was put into a bath at $90^{\circ}$, to be gradually cooled to $60^{\circ}$. After ten minutes of the bath a ther. mometer in the mouth showed $97 \cdot 6^{\circ}$, and the patient shivered. She was, however, kept in the bath for twenty-five minutes. After some violent shivering for about an hour, the temperature, which had been $96^{\circ} 8^{\circ}$, rose to $98.6^{\circ}$, and fluctuated through the night between $97.8^{\circ}$ and $98^{\circ} 6^{\circ}$. The next morm. ing the patient seemed in every respect better than on the previous afternoon. No diarrhœea occurred after this date, nor was any complaint made beyond that of more or less abdominal pain, which has occurred at intervals up to the present time. At the time of the high temperature no extra heat of skin was noticed, and the pulse-beats were only SS.

The records of temperature from this date till the 25th show variations between $96.4^{\circ} \mathrm{F}$, and $99.6^{\circ}$. On the 25 th the temperature gradually rose through the day from $97^{\circ}$ to $104 \cdot 8^{3}$ at 11 P.M., reaching at midnight $110^{\circ}$. This temperature was registered a second time by the same thermometer immediately afterwards. After a short interval $109^{\circ}$ was registered by another thermometer. Upon this the resident 
medical officer, deeming that possibly the temperature might be falling, again took the temperature in the axilla with the thermometer first used, and found it to be $1084^{\circ}$. Shortly afterwards a third thermometer held in the mouth showed $108^{\circ}$, and again! the same at 12.30 only $98^{\circ}$. The first two thermometers again used rin the axilla now showed $99 \cdot 2^{\circ}$. From this time till $1 \mathrm{~A} . \mathrm{M}$. the temperature, taken in mouth, axilla, and restum, remained at about $99^{\circ}$. At the time of the highest temperature the patient was in no way distressed. The pulse was 92 . No observation was then made of the number of respirations, but no abnormality was noticed in this respect, and I was again informed that the skin did not feel remarkably hot to the touch.

After a fluctuation between $104^{\circ}$ and $99^{\circ}$, according to records made every two hours, the temperature on the 28th was $105 \cdot 2^{\circ}$ at 10 P.M., and $109 \cdot 2^{\circ}$ at 10.55 . Ten minutes afterwards it was $99.2^{\circ}$ in axilla, $98.9^{\circ}$ in mouth, $99^{\circ}$ in rectum; pulse 96 . The patient stated that she felt very hot at this time. (She had a similar temporary feeling of heat on most of the subsequent occasions of a considerable rise of temperature.) On the 29th the temperature varied between $100^{\circ}$ and $106.5^{\circ}$ (midnight). Immediately after this last observation $97^{\circ}$ was recorded. At 3.15 A.M. on the 30 th the temperature was $110^{\circ}$, falling rapidly to $100^{\circ}$ and $96^{\circ}$. On the 30th the temperature was taken every quarter of an hour. Several times it fell to $97^{\circ}$ and $96^{\circ}$, and for two successive observations it was only $95^{\cdot} 6^{\circ}$. In the afternoon it rose to $107 \cdot 2^{\circ}$. Three successive hourly observations before midnight on the 31 st showed $103^{\circ}$, the next record being $96^{\circ}$ a little after midnight. On Feb. 2nd at 2 A.M. $110^{\circ}$ was registered, falling rapidly to $102^{\circ}, 100^{\circ}, 99^{\circ}$, and $98.5^{\circ}$. In the next hour $104^{\circ}$ was noted, and on Feb. 3rd at 5 P.M. $109 \cdot 6^{\circ}$. Temperatures as high as $105^{\circ}$ and over were registered every evening till the 15th: for example, $108^{\circ} 6^{\circ}, 109^{\circ}, 107 \cdot 6^{\circ}, 105 \cdot 9^{\circ}, 107^{\circ} 2^{\circ}, 109 \cdot 6^{\circ}$, from the 8th to the 13th of February. On the 19th there was an early morning temperature of $109.4^{\circ}$.

Having inferred from these and other observations that the high temperatures lasted for but a short time, and that possibly the highest might have been missed, I now had a registering thermometer strapped in the axilla, and noted every twenty-four hours. This was done every day till March 2nd. On each removal the index showed a temperature over $108^{\circ}$; the highest records being $111 \cdot 6^{\circ}, 110 \cdot 5^{\circ}, 110^{\circ}$, and, on four occasions, over $109^{\circ}$. During this period of the observations with the maximum thermometer, the following temperatures were taken in the mouth-namely, $108 \cdot 6^{\circ}$ at $2.30 \mathrm{~A} . \mathrm{M}$. on Feb. $23 \mathrm{rd} ; 108.8^{\circ}$ at midnight on Feb. 24 th (the maximum thermometer read at the time giving $1094^{\circ}$ ); $107.8^{\circ}$ at 10.20 P.M. on Feb. 25th (the maximum, noted at midnight, showing $111 \cdot 6^{\circ}$ ); $107 \cdot 4^{\circ}$ at 9.30 P.M. on Feb. 26th (maximum, at midnight, $109^{\circ}$ ). The temperature now being taken in the mouth only about every four hours, the highest so noted was $103.7^{\circ}$ at 4 P.M. on the 27 th the maximum showing $\left.110.5^{\circ}\right)$. On the 28 th at 4 A.M. the mouth temperature was $104 \cdot 6^{\circ}$ (maximum $109 \cdot 6^{\circ}$ ).

On the 2nd of March, I took the patient under my care at the Westminster Hospital, Dr. Sturges having very kindly offered me a bed for the purpose. There continued to be a frequent recurrence of high temperatures $\left(108^{\circ}\right.$ to $\left.111^{\circ}\right)$ on the fixed thermometer; the temperature taken in the ordinary way, sometimes in the mouth, sometimes in the other axilla, being often over $105^{\circ}$. On the 11 th and 12th March, $109^{\circ} 4^{\circ}$, and on the 13 th and $14 \mathrm{th}, 108.4^{\circ}$, were noted as evening temperatures. On the $20 \mathrm{th}$, between 4 and 8.30 P.M., $111^{\circ}$ was registered by the maximum thermometer. On the 23rd, at 6 P.M., the house-physician registered $107 \cdot 2^{\circ}$ in the right axilla; the maximum thermometer, which had been in the left axilla for only half an hour, showing $107 \cdot 8^{\circ}$. Five minutes afterwards the temperature in the mouth was found to be $988^{\circ}$, and in the right axilla $986^{\circ}$. At the time of the high temperature the pulse was 102 , and the respiration 32, while the skin was reported to feel very hot to the touch. With the fall of the temperature the respiration fell to 24 .

No more observations were made with the maximum thermometer for some time after this date. The highest temperature subsequently observed at the Westminster Hospital was $105^{\circ}$ on the night of the $23 \mathrm{rd}$. The patient, having been kept awake for twenty-four hours for the purpose of frequent estimations of urea and the taking of halfhourly temperatures, was left unobserved till the night of the 25th. During this time she stated that she had had once a feeling of heat, as was usual with her at the probable time of most of the higher temperatures. Continuous observation made during the night of the 25th showed only subnormal temperatures. On March 27th, the patient, feeling quite well, with the exception of some slight pain in her back, returned at her own request to her work of nurse at the Children's Hospital. During her stay at the Westminster Hospital she had complained for a few days of considerable dysuria. The urine was found to contain a little blood, some renal and a quantity of vaginal epithelium, and about one-third albumen. The urine became normal in all respects in the course of a day or two, as the pain disappeared. On admission to the Westminster Hospital, albumen was proved absent from the urine, as it had been on previous examinations. The bowels were torpid ever since the enteric diarrhoea ceased; and there had been no catamenial discharge, with the exception of a very slight flow at the end of February, since the beginning of the year. Frequent examination as yet had failed to detect any disease of other organs, nor was any other disorder discovered or complained of. No examination was made of the uterus \&c. up to the time of the patient's leaving the hospital. Her general appearance was healthy, and she had gained flesh considerably.

After the patient's return to the Children's Hospital, her temperature, taken four times a day, ranges between $95^{\circ}$ and $102.8^{\circ}$. On April 8th, $1024^{\circ}$ was registered at 9.30 P.M., and exactly a quarter of an hour afterwards $99^{\circ}$. The maximum thermometer, which has been in use again from April 6th to present date (April 25th), read off every morning and evening, varies between $102^{\circ}$ and $108^{\circ} 6^{\circ}$, a very frequent registration being $104 \cdot 6^{\circ}$. Temperatures higher than $106^{\circ}$ have occurred only since the 18th, from which date till the 25th the lowest maximum reading has been $105^{\circ}$. The pulse, observed morning and evening, varies between 70 and 100 ; the number of respirations being rarely less than 32 , generally higher, and rising on slight exertion to 50 or more. For the last few weeks the patient has complained of frequent sickness, renewed dysuria, pain in the abdomen (chiefly on the left side), and constipation. On the 18th Dr. Fancourt Barnes made a thorough examination of the pelvic organs at my request, the patient being under chloroform. He found the uterus retroflexed, and the left ovary displaced and lying by the side of the os uteri.

The patient still complains of considerable pain in the left side of abdomen, and is frequently sick. The higher temperatures have been of more frequent occurrence since the uterine examination on the 18th. The urine, examined on the 24th, was found to contain a slight cloud of albumen, and the patient states that for two or three nights she found her ankles were puffy on going to bed, but that this symptom did not continue. No oedema is now detectable (April 25th). The catamenia have not appeared.

The extreme abnormality of the temperatures in this case, with their want of connexion with the general symptoms of pyrexia, or signs of tissue-destruction, and their isolation from any known cause, moreover, what is still more remarkable, the rapid fall to a normal or often subnormal point, render necessary some comment on the nature of the evidence for the facts alleged. The sudden heating of the body without serious symptoms is, I apprehend, as difficult of explanation as the extremely rapid cooling.

The following objections may be urged against the genuineness of the facts:- 1 , error on the part of the observer ; 2 , inaccuracy of the instruments used in observation; and, 3 , imposture on the part of the patient. These sources of fallacy must be briefly discussed.

1. The chief observers of these facts (besides myself) were Mr. Spooner (resident medical officer at the Children's Hospital), Miss Mackenzie (the lady superintendent of nursing there), and Mr. Hayward (house physician at the Westminster Hospital). Each of these observers is known to me and several others as having had considerable experience in thermometric observation, and as being both capable and trustworthy. It may fairly be admitted, then, that the thermometers used really registered the reported temperatures.

2. The objection of the possible inaccuracy of the thermometers fails from the fact that several were used in the course of the case. Often two were used simultaneously, and in one series of observations-viz., of the falling temperature - on Jan. 28th, three were employed.

3. It is often difficult to exclude the element of imposture from an investigation of fact; but, omitting all collateral arguments derived from want of motive, and great desire on the part of the patient to get back to her work, I would call 
attention to the following important facts antagonistic to the theory of imposture, with especial reference to the two tricks which obviously suggest themselves-viz., manual or axillary friction of the thermometer, and the placing in its neighbourhood of some extraneous source of heat, such as a small vessel containing hot water or even a heated coal, both of which theories have been propounded by several physicians who have kindly seen the case with me. (a) Four temperatures ranging between $107.4^{\circ}$ and $108 \cdot 6^{\circ}$ were observed by Miss Mackenzie, the thermometer being placed in the mouth, and the patient persistently watched. $(b)$ A temperature of $106^{\circ}$ was observed by myself on March 2 nd, the axilla having been carefully examined, and the patient's hands being in view during the whole time of the observation. (c) A temperature of $108.4^{\circ}$ was taken on March 13th by Mr. Hayward, who kept in view the patient's hands continuously. (d) A temperature of $109.4^{\circ}$ was taken on March 12 th by the night nurse at the Westminster Hospital, who states that the patient was asleep during the observation, having been awakened for the insertion and removal of the thermometer. The nurse further states that she held one of the patient's hands, and saw the other, the whole time. $(e)$ A temperature of $105 \cdot 2^{\circ}$ was taken on the 18th of April by a thermometer put in the axilla at 5 o'clock, and taken out at 9 o'clock, during the whole of which time the patient was partially under the influence of chloroform. She had to be awakened both for the insertion and removal of the instrument. At 4.30, the patient being then fully under chloroform, the temperature of $95^{\circ}$ was three times carefully taken in the axilla. ( $f$ ) On Feb. 21st $106^{\circ}$ and $105.9^{\circ}$ were shown by a registering and non-registering thermometer respectively, held simultaneously in the mouth. This observation was made for me by Miss Mackenzie, as one of a series, several of which served to prove, by the marked difference between the two thermometers, the short duration of the high temperatures. $(g)$ On one occasion, at my request, Mr. Spooner fixed a thermometer in the axilla with strapping, and strapped the patient's corresponding arm immovably to her side, covering the thermometer with strapping, and placing seals thereon in such a manner as to render it apparently impossible for the instrument to be reached without detection. On removal of the strapping, $109 \cdot 6^{\circ}$ was noted, It may be remarked, in conclusion, that it is very difficult, even with prolonged and energetic rubbing with some dry substance, to raise the mercury of a clinical thermometer above $104^{\circ}$; in a moist axilla or a wet and smooth-walled mouth I do not think it can be done.

I believe that due consideration of the above evidence will negative imposture in this case, and therefore submit these observations to the profession, as probably facts of great importance, omitting all conjecture as to the cause of the phenomena, nor attempting to connect them with the few signs of disorder as yet revealed by examination.

\section{THE ARTIFICIAL PRODUCTION OF HUMAN DISEASES IN THE LOWER ANIMALS.}

BY W. LAUDER LINDSAY, M.D., F.R.S.E., PHYSICIAN TO THE MURRAY ROYAL INSTITUTYON, PERTH.

(Concluded from p. 565.)

"THE production of thyroid tumours in animals by the administration of substances derived from the water or soil of countries where goitre is endemic," formed the subject of one of the prizes of the French Academy of Medicine in 1874. ${ }^{1}$ A case of bronchocele in the dog was shown by Dr. Morell Mackenzie at the Pathological Society of London in May, 1874: he described it as a fibro-cystic disease of the thyroid, or fibro-cystic goitre. At the same meeting of the said Society it was stated that bronchocele is " rare in dogs, even in Derbyshire." But Dr. Crisp remarked, on the other hand, that on the South American mountains, above a certain height, all the dogs are affected with goitre." "Baillarger states that horses and mules become affected by drinking the water of the Isère, which ...... contains much calcareous salts. ...... Not man alone is affected with goitre 1 As reported in the British Medical Journal, April 11th, 1874, p. 494.
Ibid., May 30th, 1874, p. 710-11. in the goitrous districts, but also dogs and cats," according to Blyth.

Small-pox has been communicated to monkeys of the genus Cercopithecus, by Dr. Zuelzer of Berlin. ${ }^{3}$ A fatal case of small-pox in a pet red-bird is recorded as having occurred at Chicago in 1876 ; the disease having been contracted from its master, who was recovering from it. ${ }^{4}$ Cow. pox in the young hound was produced by vaccination in the hands of Jenner and Berkeley. According to Williams, small-pox and cow-pox are identical diseases ; but Chavean's experiments led him to a different conclusion. ${ }^{5}$

Erysipelas was produced in certain animals by inoculation in the experiments of Arth and Lukomsky. ${ }^{6}$

Fatal septiccemia, artificially induced, has occurred in the rabbit and other animals. Under the name of "putrid infection," or " putrid fever," it resulted from the inoculation of putrid blood in rabbits and dogs, in the hands of Dr. Gesualdo Clementi and Dr. Thin, whose experiments were confirmatory of those of Sanderson and Klein, Davaine, and others. Death was preceded by convulsions. In one case there was ulceration of Peyer's patches; in another, pleuritic exudation. ${ }^{7}$ Septicæmia ${ }^{8}$ was produced in the rabbit by Dr. Richardson, who inoculated fluid from the peritoneum of a human patient suffering from surgical fever, the said flud being supposed to contain a poisonous organic base called by him "septine." What he described as "putrid fever" was produced in dogs by Professor Binz of Bonn, by inject. ing putrid ichor, or putrefying blood, under the skin. Under such circumstances, " all the symptoms appear which are to be observed in human beings suffering from putrid fever." 10 But the administration of alcohol diluted with water, either hypodermically injected or given by the stomach, materially and favourably modified the course and fatality of the fever. ${ }^{1 l}$ In a discussion on Pyæmia at the Clinical Society of London, Mr. Hulke stated "we can produce in the lower animals, by the introduction of pus, all the symptoms of pyæmia. ${ }^{12}$ Uræmic poisoning also occurs from the hypodermic injection of urea, the symptoms-including unconsciousness and convulsions-being similar to those exbibited sometimes in the course of scarlet fever in man, according to Richardson.

Professor Simonds ${ }^{13}$ has pointed out that the infection of typhoid fever may be communicated to healthy pigs by men who have been in contact with diseased ones-for instance, in slaughtering them. And this is a fact of serious import, considering the frequency and fatality of typhoid fever in pigs, and the tendency of butchers in our large cities to sell for human consumption the flesh of the diseased animals. For instance, at Bradford, where an epidemic (or epizootic, as veterinarians prefer to call it) of fatal typhoid ferer in pigs occurred in the beginning of 1876 , a pork butcher was, by the WestRiding magistrates, committed to prison for two months for having sold some of the diseased flesh of the dead animals. ${ }^{15}$ Wallace, in "his Malay Archipelago," speaks of an illness in a young captive orang "which ran its course like an intermittent fever, and killed it;" the disease "exhibited phenomena altogether human-like." Probably it was intermittent fever. A Natal lion died of fever in the Zoologieal Gardens, Dublin, in $1864 ; 15$ but in this case, as in so many others, we are not told what was the precise nature of the fever. What is called "low" fever is frequently fatal among donkeys on the east coast of Africa ${ }^{16}$ - a fever that may or may not be intermittent, or typhus.

Glycosuria (diabetes mellitus) has been artificially induced in various animals by Eckhard, Tieffenbach, Pavy, Schiff, and others, by some of the following means ${ }^{17}$ :- (1) Injury of

3 According to Mr. Jonathan Hutchinson, in a clinical lecture on "Hospital Plagues," in the Brit. Med. Jour., Feb. 7th, 1874, p. 162. 4 Graphic, May 27 th, 1876 , p. 527.

5 Notice of Williams's "Veterinary Medicine" in Brit. and For. Med. Chir. Review, April, 1875, p. 420.

6 Braidwood and Vacher's Report on the "Life-History of Contaginm," Brit. Med. Jour. 1876, p. 76.

7 As quoted by Mr. Hutchinson in Brit. Med. Jour., Feb. 7th, 1874, p. 183. "poisoning of the blood from every source" as recommended by Prof. Bennett in Brit Med. Jour., March 14th, 1874, p. 340 .

9 Nature, Aug. 31st, 1876, p. 370 . 10 Ibid., Dec. 18th, 1873, p. 132. 11 As reported in the Practitioner for 1876.

13 In his "Report on the Health of Animals of the Farm," in the Journal of the Royal Agricultural Society of England for April, 1875.

Ju Daily Telegraph, Jan. 28th, 1876.

15 Daily Telegraph, Jan. 28th, 1876.

16 Brit. Med. Jour., June 24th, 1876, p. 794.

17 According to Dr. Lauder Brunton, in his Lectures on the Pathology and Treatment of Diabetes Mellitus, Brit. Med. Jour., Jan. 1874, p. 40-1, and Feb. 21st, 1874, p. 222 . 